\title{
VOC AND PARTICLE CONCENTRATIONS IN NEW AND OLD MODEL AUTOMOBILES
}

\author{
J. EDWARD DOTHEROW, DEONTE MARTIN \& ATIN ADHIKARI \\ Jiann-Ping Hsu College of Public Health, Georgia Southern University, USA
}

\section{ABSTRACT}

Volatile organic compounds (VOCs) emitted from vehicle dashboards, panelling and interior components are one of the primary contributors to poor automobile air quality. Exposure to VOCs can result in symptoms such as headaches and fatigue which can lead to unsafe driving. The purpose of this pilot study was to compare the VOC and airborne particle concentration levels between new model $(<10$ years old, $N=6$ ) and old model ( $>10$ years old, $N=4$ ) automobiles. VOC and particle measurements were conducted at the beginning of business operations and then again four hours later to assess the impact of temperature on material emissions of VOCs. Morning VOC measurements in new and old model automobiles ranged from $<\mathrm{LOD}$ to $6.60 \mathrm{ppm}$ (mean \pm SD: $1.168 \pm 2.005 \mathrm{ppm}$ ) and $<\mathrm{LOD}$ to $0.60 \mathrm{ppm}$ (mean \pm SD: $0.0285 \pm 0.0182$ ), respectively. Afternoon VOC measurements for both models ranged from 0.22 to $6.62 \mathrm{ppm}$ (mean \pm SD: $2.952 \pm 1.714 \mathrm{ppm}$ and $<$ LOD to $12.12 \mathrm{ppm}$ (mean \pm SD: $3.106 \pm 3.722$ ), respectively. Interestingly, unlike new model automobiles, old models of automobiles showed statistically significant positive correlations between temperature increase and VOC levels [Spearman's rho in the mornings: $0.611(p<0.05$; in the afternoons: $0.947(p<0.05)$ ]. New model automobiles emit significantly higher levels of VOCs than older models during morning hours $(p<0.05)$.

Keywords: automobiles, materials emissions, temperature, volatile organic compounds

\section{INTRODUCTION}

Volatile organic compounds (VOCs) are a category of organic chemical compounds whose structure allows them to evaporate under normal temperature and pressure conditions [1,2]. VOCs are emitted into the air from processes (such as burning fuels) or naturally by being released by products (such as building materials) [2]. VOCs are emitted from car interior products such as dashboards, door panels, vinyl and plastics and are a primary contributor to poor air quality in automobiles. Automobile products can emit VOCs for a long period of time as a result of off-gassing, heating and cooling, and the natural breakdown of products due to aging [3]. Exposure to VOCs can result in symptoms such as nausea, fatigue and headaches which could lead to unsafe driving $[2,4]$.

Many studies investing VOC emission rates have been conducted. These studies have provided insight into levels of harmful compounds such as benzene and toluene in automobile cabins. The emission rates have been analysed under varying conditions such as engine idling vs driving and the effect of ventilation [4-6]. Further investigations have shown the influence of temperature on VOC emissions. Several studies have shown that as the temperature increases in the cabin of automobiles, so do the levels of VOCs [4,7-9].

Like VOCs, particulate matter (PM) is a class of air pollution that can be found in automobiles. PM is made up of either solid or liquid particles that are suspended in the air and have a certain chemical structure such as sulphur or nitrogen oxides [1]. PM is formed in many different ways including fuel burning (wood-burning, power plants), driving on unpaved roads, and from natural sources such as pollen and dust [1]. Particles are grouped by size according to their aerodynamic diameter, which is determined by its density and shape. Exposure to PM can lead to respiratory problems such as exacerbated asthma, decline in pulmonary function and respiratory diseases [1]. 
While there are many studies investigating VOC emission rates and temperature, a majority of them gather their data from new cars. There is little data comparing the VOC concentration in new and old model automobiles. The purpose of this pilot study was to investigate the emission of VOCs in new model automobile ( $<10$ years old) and old model automobiles ( $>10$ years old) in two different times of the day - morning and afternoon hours - with different temperatures. We examined the influence of in-cabin temperature on materials emission of VOCs and number concentrations of particles of following six sizes: $0.3,0.5,1.0,2.5,5.0$ and $10 \mu \mathrm{m}$.

\section{METHODS}

\subsection{Sampling locations}

Data were collected from two business parking lots in southeast Georgia, USA. The two parking lots were within four miles of each other. Neither parking lot provided cover for vehicles, and both were free of tree coverage. Data were collected from five vehicles at each site. All vehicles were parked in spots next to each other and were not moved in-between sampling periods.

\subsection{Data collection and analysis}

A total of ten new $(N=6)$ and old $(N=4)$ model vehicles were recruited for this pilot study through convenience sampling. New model automobiles $(<10$ years old) ranged in production year from 2013 to 2017 . Old model automobiles ranged in production year from 1997 to 2005. VOC and particle data were collected from each vehicle twice per day. The first measurements were taken between 8 am and $9 \mathrm{am}$. The second set of data collection took place $4 \mathrm{~h}$ later between $12 \mathrm{pm}$ and $1 \mathrm{pm}$. VOC data were collected using a VOC08 meter (General Tools, NJ, USA). The VOC08 detects VOCs by measuring changes in the conductivity and resistance electrical properties in metal-oxide sensors when exposed to ambient gases [10]. During each collection, VOC levels were measured every $15 \mathrm{~s}$ for $3 \mathrm{~min}$. Temperature and particle counts $\left(\mathrm{n} / \mathrm{m}^{3}\right)$ were measured in 15 -s intervals for 3 min using a 6-channel $(0.3,0.5$, $1,2.5,5$ and $10 \mu \mathrm{m})$ particle counter (CEM, West Bengal, India). The DT-9881 is an optical particle counter that uses light refraction to indicate the size of particles pulled into the device [11]. The DT- 9881 has a flow rate of $2.83 \mathrm{~L} / \mathrm{min}$ and detects $\mathrm{CO}, \mathrm{HCHO}$, relative humidity and temperature in addition to the six particle sizes stated above. Statistical analysis was preformed using SPSS Version 25 (IBM, NY, USA). Nonparametric Spearman's correlation tests were ran for determining the association between the mean value of VOCs and temperature as well as the association between particle concentration and temperature. Pearson correlation test was used to determine the relationship between temperature and VOCs.

\section{RESULTS AND DISCUSSION}

Morning VOC measurements in new model vehicles ranged from below the level of detection $(<\mathrm{LOD})$ to $6.60 \mathrm{ppm}$ (mean $\pm \mathrm{SD}: 1.168 \pm 2.005 \mathrm{ppm})$ Old model vehicles ranged from $<$ LOD to $0.60 \mathrm{ppm}$ (mean \pm SD: $0.0285 \pm 0.0182$ ). VOC measurements for new model vehicles in the afternoon ranged from 0.22 to $6.62 \mathrm{ppm}$ (mean \pm SD: $2.952 \pm 1.714$ ppm Afternoon VOC measurements for old model vehicles ranged from below the level of detection to $12.12 \mathrm{ppm}$ (mean $\pm \mathrm{SD}: 3.106 \pm 3.722$ ). VOC concentrations for both new and old model automobiles in the morning and afternoon hours are shown in Fig. 1. 


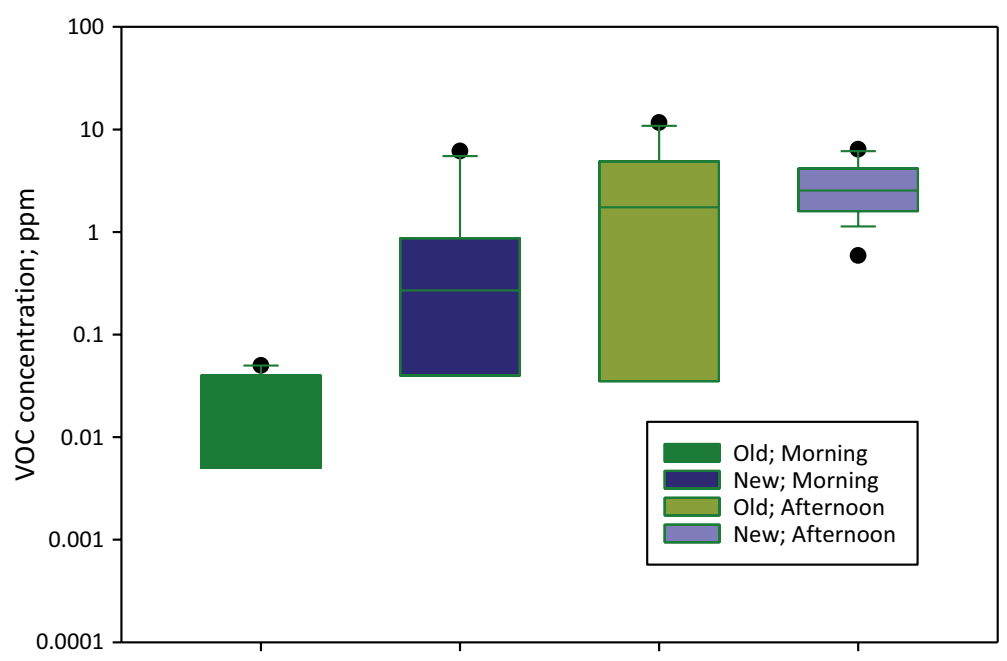

Figure 1: VOCs in old and new models by measurement times.

Morning temperatures in new model vehicles ranged from $20.6^{\circ} \mathrm{C}$ to $36.7^{\circ} \mathrm{C}$ (mean $\pm \mathrm{SD}$ : $28.16 \pm 3.97^{\circ} \mathrm{C}$ ). Old model morning temperatures ranged from $27.2^{\circ} \mathrm{C}$ to $33.7^{\circ} \mathrm{C}$ $\left(\right.$ mean $\left.\pm \mathrm{SD}: 30.36 \pm 2.23^{\circ} \mathrm{C}\right)$. Afternoon temperatures in new model vehicles ranged from $24.8^{\circ} \mathrm{C}$ to $38.5^{\circ} \mathrm{C}\left(33.82 \pm 3.37^{\circ} \mathrm{C}\right)$. Old model temperatures ranged from $30.3^{\circ} \mathrm{C}$ to $44.6^{\circ} \mathrm{C}$ (mean \pm SD: $35.58 \pm 4.01^{\circ} \mathrm{C}$ ).

VOCs and temperature showed statistically significant correlations in three of the four analyses. Temperature and VOCs in old vehicles showed significant correlation in both the morning and afternoon with Pearson correlation coefficients of $0.662(p<0.001)$ and 0.917 $(p<0.001)$, respectively. New model vehicles showed a statistically significant correlation in the morning, but not in the afternoon (Pearson coefficient of $0.491, p<0.001$ ).

Particle concentrations in new models were significantly higher in the morning than in the afternoon for $0.3 \mu \mathrm{m} p<0.05), 0.5 \mu \mathrm{m}(p<0.001)$ and $1 \mu \mathrm{m}(p<0.05)$. Larger particles of 2.5, 5.0 and $10 \mu \mathrm{m}$, however, showed no significant differences. Particle concentrations in old models were significantly higher in the morning than in the afternoon for $0.3 \mu \mathrm{m}(p<0.05)$, $0.5 \mu \mathrm{m}(p<0.001), 1 \mu \mathrm{m}(p<0.001), 2.5 \mu \mathrm{m}(p<0.001), 5 \mu \mathrm{m}(p<0.001)$ and $10 \mu \mathrm{m}$ $(p<0.001)$. Particle concentrations for old and new models in the morning and afternoon are shown in Figs. 2 and 3.

The results of this study align with those of other studies measuring VOC concentration and temperature in automobile cabins. Yang et al. (2017) found that temperature influences VOC concentration. In their study, they found that as temperature increased so did the concentration of five different VOCS (benzene, toluene, styrene, ethylbenzene and $p$-xylene) with toluene showing the greatest increase [8]. Likewise, Xiong et al. found that temperature influences the VOC concentration in automobile cabins in a linear relationship [7]. When comparing VOC concentration during warm $\left(26^{\circ} \mathrm{C}\right)$ and extreme heat $\left(60^{\circ} \mathrm{C}\right)$ conditions, Fedoruk and Kerger [3] found that in extreme heat conditions VOC concentration rates were four times higher than those found in warm conditions.

The results of this study found that new model automobiles emit higher levels of VOCs than older models in the mornings comparison. These results are similar to other studies that 


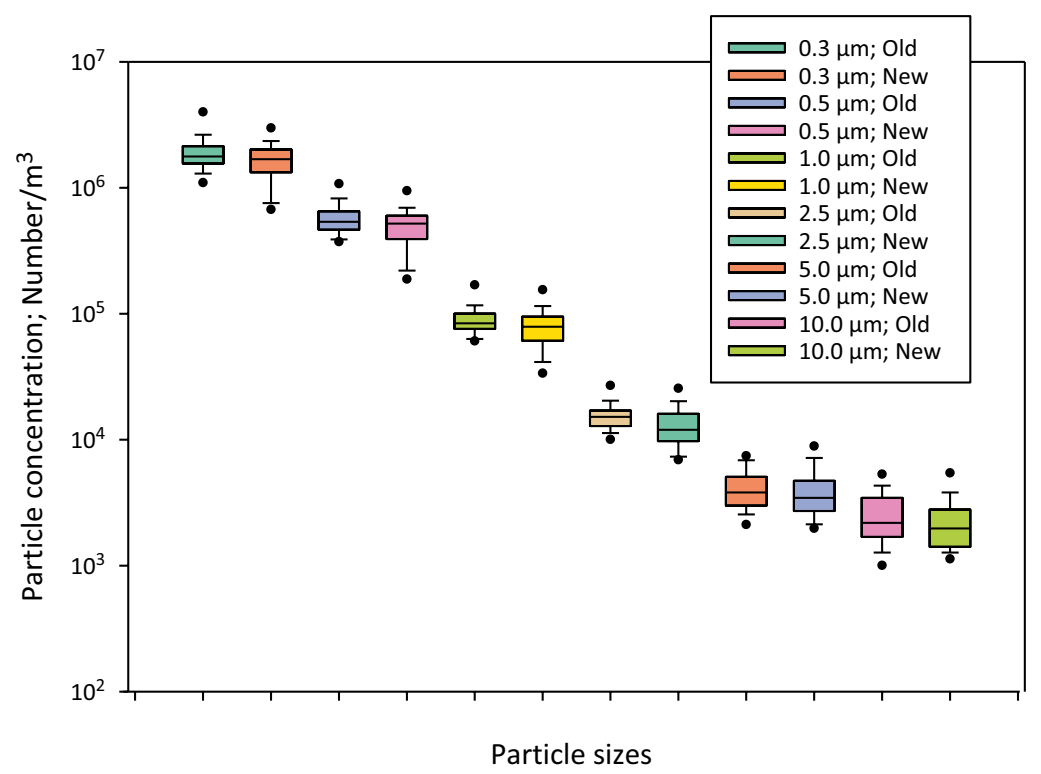

Figure 2: Morning particle concentrations.

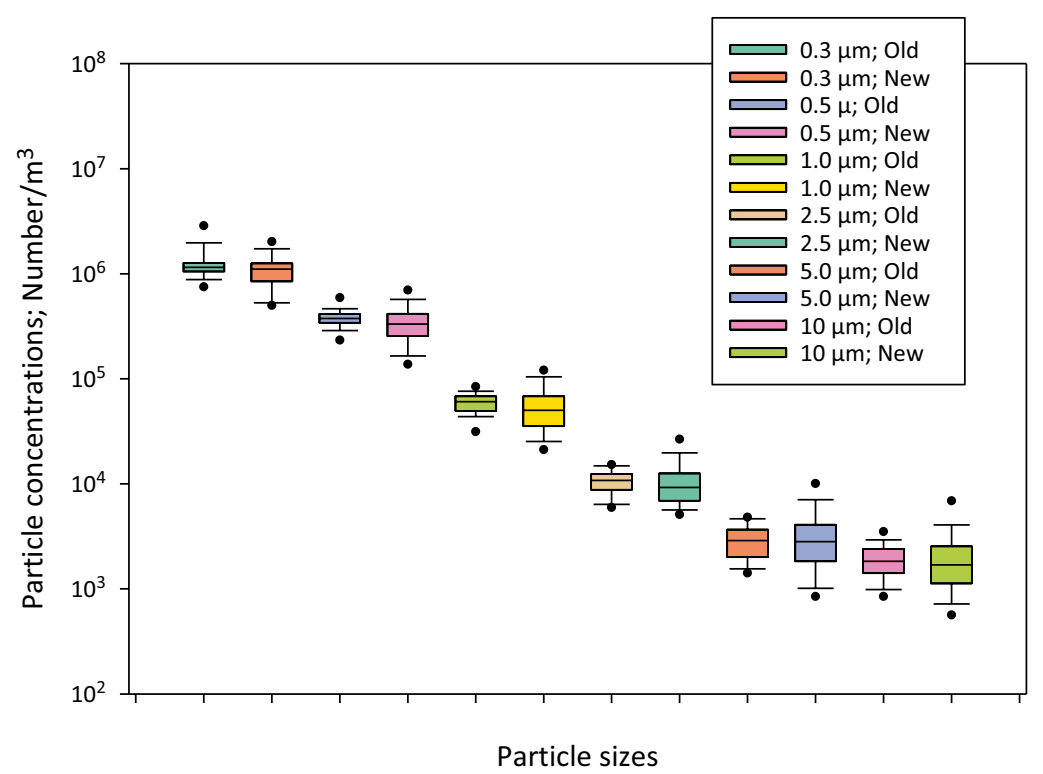

Figure 3: Afternoon particle concentrations. 
have compared the two different models. You et al. [12] found VOC concentrations in new vehicles to be four times higher than that of a 1-year old vehicle and almost 40-times higher than that of a 5-year-old vehicle. In a similar study, Fedoruk and Kerger [3] found that in addition to temperature, the age of vehicle influences the emission of VOCs into the cabin. They found that newer vehicles had higher concentrations of VOCs than older models.

While the results showed significant differences between morning and afternoon PM concentrations, no significant difference was found between old and new vehicles. The lack of difference between the old and new models can be explained in two ways. First, the cabin of automobiles is a closed environment with limited air flow to disperse the particles. PM is generated by car engines and dispersed into the air from the exhaust pipe. Ristovski et al. found that, depending on the size and type, engines emit particles ranging 0.5-30 $\mu \mathrm{m}$ [13]. In addition to those produced by the engine, PM is produced by tires rolling on the ground and found in the air [1]. PM produced by the engine and those found outside can enter the cabin through the air vents or unsealed areas connecting the cabin with the engine bay.

Second, the lack of significant difference in particle concentration may be associated with the VOCs found in the automobiles. Li et al. found that in an indoor environment, ozone and VOCs can mix to form hydrogen peroxide. When ozone and limonene were both present, particle concentrations were significantly higher than when only one or neither were present [14]. In a similar study, Fan et al. found that a mixture of ozone and VOCs in an indoor environment can result in the production of hydrogen peroxide, submicron particles and ultra-fine particles [15]. According to United States Environmental Protection Agency, ground level ozone is highest during the late-spring and summer months due to hot and dry climate [16]. The mixing of ozone and VOCs in the automobile cabins may explain the similar concentration of particles between the two different models.

This study has a number of limitations. First, as a pilot study the scope is limited. Only ten automobiles were included in the study which limits the impacts of the findings. Second, the duration of the sampling time is a limitation to this study. VOC levels steadily rose throughout the measurement period. Limiting the time of measurement to 3 min may underestimate the concentration of VOCs in automobile cabins.

\section{CONCLUSSION}

As temperature increases in the cabin of an automobile, the VOC concentration increases as well. New model vehicles emit higher levels of VOCs than old model vehicles.

\section{ACKNOWLEDGEMENTS}

This study was partially supported by the funding from the Office of the Vice President for Research \& Economic Development (VPRED) and Jiann-Ping Hsu College of Public Health, Georgia Southern University.

\section{REFERENCES}

[1] Frumkin, H., (ed), Environmental Health: From Global to Local, Jossey-Bass: San Francisco, pp. 319-339, 2016.

[2] Volatile Organic Compounds' Impact on Indoor Air Quality, Indoor Air Quality; U.S. Environmental Protection Agency, available at https://www.epa.gov/indoor-air-quality-iaq/volatile-organic-compounds-impact-indoor-air-quality (accessed 8 December 2018). 
[3] Fedoruk, M.J. \& Kerger, B.D., Measurement of volatile organic compounds inside automobiles. Journal of Exposure Science and Environmental Epidemiology, 13, pp. 31-41, 2003.

[4] Brebbia. C.A., (ed), Environmental Health V, WIT Press: Southhampton, pp. 3-11, 2009.

[5] Chien, Y.C., Variations in amounts and potential sources of volatile organic chemicals in new cars. Science of the Total Environment, 382, pp. 228-239, 2007.

[6] Kim, KH., Szulejko, J.E., Jo, HJ., Lee, MH., Kim, YH., Kwon, E., Ma, CJ. \& Kumar, P., Measurements of major VOCs released into the closed cabin environment of different automobiles under various engine and ventilation scenarios. Environmental Pollution, 215, pp. 340-346, 2016.

[7] Xiong, J., Yang, T., Tan, J., Li, L. \& Ge, Y., Characterization of VOC emission from materials in vehicular environment at varied temperatures: correlation development and validation. PLOS ONE, 10(10), p. e0140081, 2015. DOI: 10.1371/journal. prone.0140081.

[8] Yang, T., Zhang, P., Xu, B. \& Xiong, J., Predicting VOC emissions from materials in vehicle cabins: determination of the key parameters and the influence of environmental factors. International Journal of Heat and Mass Transfer, 110, pp. 671-679, 2017.

[9] Muller, D., Klingelhofer, D., Uibel, S. \& Groneberg, D.A., Car indoor air pollution analysis of potential sources. Journal of Medicine and Toxicology, 6(1), p. 33, 2011. DOI: 10.1186/1745-6673-6-33.

[10] Spinelle, L., Gerboles, M., Kok, G., Persijn, S. \& Sauerwald, T., Review of portable and low-cost sensors for the ambient air monitoring of Benzene and other volatile organic compounds. Sensors, 1797, 1520, 2017. DOI: 10.3390/s17071520.

[11] Heim, M., Mullins, B.J., Umhauer, H. \& Kasper, G., Performance evaluation of three particle counters with an efficient "multimodal" calibration method. Journal of Aerosol Science, 39, pp. 1019-1031, 2008.

[12] You, K., Ge, Y., Hu, B., Ning, Z., Zhao, S., Zang, Y. \& Xie, P., Measurement of invehicle volatile organic compounds under static conditions. Journal of Environmental Sciences, 19, pp. 1208-1213, 2007.

[13] Ristovski, Z.D., Morawska, L., Bofinger, N.D. \& Hitchins, J., Submicrometer and supermicrometer particle emission from spark ignition vehicles. Environment International, 32(24), pp. 1188-1195, 2009.

[14] Li, TH., Turpin, B.J., Shields, H.C. \& Weschler, C.J., Indoor hydrogen peroxide derived from ozone/d-limonene reactions. Environmental Science \& Technology, 36(15), pp. 3295-3302, 2002.

[15] Fan, Z., Weschler, C.J., Han, I.K. \& Zhang, J., Co-formation of hydroperoxides and ultra-fine particles during the reactions of ozone with a complex VOC mixture under simulated indoor conditions. Atmospheric Environment, 39(28), pp. 5171-5182, 2005.

[16] Latest findings on national air quality - 2002 status and trends. U.S. Environmental Protection Agency. Office of Air Quality Planning and Standards Emissions, Monitoring, and Analysis Division. Research Triangle Park, NC, available at https://nepis.epa. gov/Exe/ZyPDF.cgi/P1003URM.PDF?Dockey=P1003URM.pdf (accessed 24 February 2019). 